\title{
Endobronchial hamartoma with recurrent pneumonia
}

\author{
Deya Ghosh Chatterji ${ }^{1}$, Mitali Banerjee ${ }^{2}$, John O Thayer ${ }^{3}$ and Tapas Bandyopadhyay ${ }^{4 *}$ \\ ${ }^{1}$ NKP Salve Medical College, Nagpur, India \\ ${ }^{2}$ Neurobiology Major, University of Connecticut, USA \\ ${ }^{3}$ St. Francis hospital, Hartford, USA \\ ${ }^{4}$ Frank H Netter School of Medicine, Quinnipiac University, USA
}

\begin{abstract}
A middle-aged man presented with recurrent left lower pneumonia. Bronchoscopy showed a left lower lobe mass almost completely blocking the left lower lobe bronchus. A pulmonary hamartoma was diagnosed and successfully resected. Pulmonary Hamartomas are benign lung tumors. Endobronchial lesions can cause recurrent pulmonary infection. Diagnosis is made by chest imaging and biopsy. Resection leads to a complete cure.
\end{abstract}

\section{Case report}

A 53-year-old Caucasian man presented with recurrent cough and dyspnea for 4-5 years. He had no prior history of pulmonary disease and never smoked. He had several courses of antibiotics over the years. 2 months prior to his current presentation he had a particularly severe and prolonged bout of cough and phlegm associated with left lower chest discomfort and fever. He saw his primary care physician and was prescribed a 10-day course of Levofloxacin. A chest radiograph was obtained and showed a left lower lobe infiltrate. He had a follow up chest radiograph 4 week after treatment. His follow up radiograph did not show any improvement in the infiltrate.

He was seen in our office in consultation. He appeared well. Vitals were stable. There was no clubbing of fingers or lymphadenopathy. Chest exam revealed decreased breath sounds over the lower left chest posteriorly with bronchial breath sounds and aegophony. Remainder of his examination was normal. Lab testing including a CBC, HIV test and immunoglobulin profile was unremarkable. Pulmonary function testing was normal. A Computed Tomography (CT) of the chest was obtained and representative cuts are shown (Figures 1 and 2). A bronchoscopy showed a smooth lobulated mass occluding the left lower lobe orifice. Endobronchial biopsies were obtained and showed features suggestive of a chondroid hamartoma (Figure 3). Resection of the lesion was planned because of repeated pulmonary infections.

The patient underwent a thoracotomy with intent of sleeve bronchotomy of the left lower lobe bronchus. He had a left lower lobe bronchotomy with excision of the hamartoma. The tumor was very adherent to the bronchus and difficult to remove completely. The bronchus was quite friable due to ingrowth of the tumor and repeated bouts of post obstructive pneumonia. Two attempts were made to close the bronchus both resulting in a large air leak and an unsatisfactory anastomosis. We decided the safest course was to complete a lower lobectomy with a stapled closure.

The patient tolerated the procedure and is doing well in follow up.

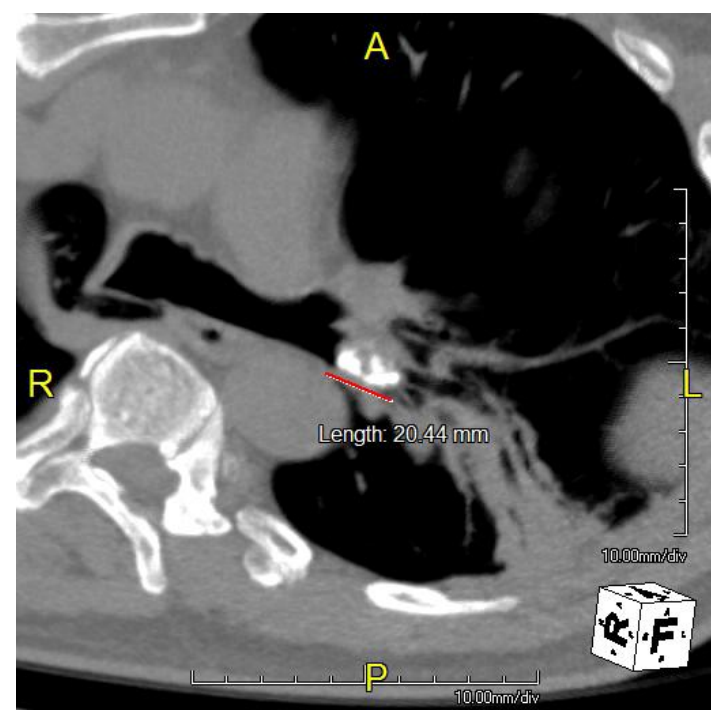

Figure 1. Mass with calcification, Left lower lobe bronchus

\section{Discussion}

Pulmonary hamartomas are benign lung tumors of lung commonly diagnosed in the fifth and sixth decades of life with a male preponderance of 3:2 [1]. They are composed of a mixture of mesenchymal and epithelial tissues. Cartilage is the most predominant mesenchymal component. Such lesions are often asymptomatic and found during routine chest imaging.

Most hamartomas are peripheral or intra pulmonary and are asymptomatic. Central or endobronchial hamartomas may present

${ }^{\star}$ Correspondence to: Tapas Bandyopadhyay, Associate Professor, Pulmonary/ Critical Care Medicine, Frank $\mathrm{H}$ Netter School of Medicine, Quinnipiac University, USA, Tel: 860-280-4519; E-mail: bpdk@sbcglobal.net

Received: March 28, 2018; Accepted: April 25, 2018; Published: April 30, 2018 


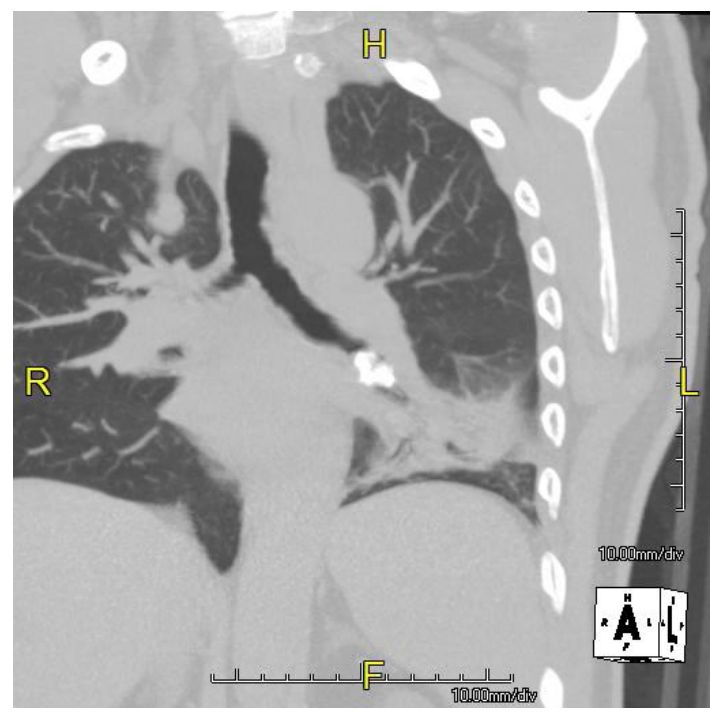

Figure 2. Mass in left lower lobe bronchus

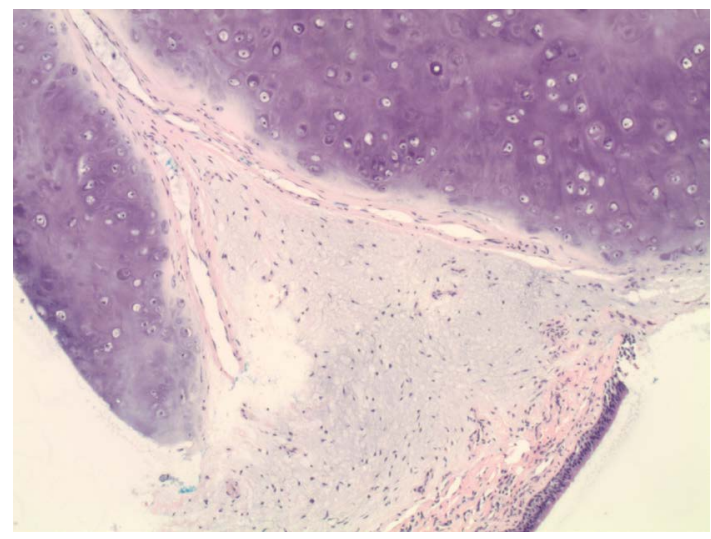

Figure 3. Biopsy showing features of a chondroid hamartoma

with features of obstruction such as cough, chest pain or pneumonia [2]. Popcorn like appearance is seen in chest radiographs in about $30 \%$ of hamartomas due characteristic calcification. This characteristic pattern of calcification and fat deposition can be more sensitively identified on a CT scan of chest [3].

Fine needle aspiration cytology (FNAC) confirms the diagnosis and distinguishes them from malignant tumors. Cytological aspirate shows a fibromyxoid stroma with spindle cells, fat spaces, sheets of bronchial epithelial cells with benign cytological features. Presence of atypical reactive bronchial cells can lead to a false positive diagnosis of malignancy [4] Highlighting the chondroid and fibromyxoid stroma using a immune cytochemical stain for S-100 protein helps to distinguish amongst the two. [5]

Although the exact genetic origin of these lesions is unknown, cytogenetic analysis has shown abnormal karyotype and recombinations between chromosomal bands 6p21 and 14q24 [6].

Regular follow-up is done with chest imaging. Long term followup has not revealed any evidence of malignancy in most cases [7] Symptomatic patients such as in the present case and large rapidly growing lesions need thoracotomy followed by enucleation as the lesion is well encapsulated or a segmental resection [2]. Recent reports show various methods of successful endobronchial resection of endobronchial hamartomas using laser or electrocautery snare, cryotherapy, argon plasma coagulation, or combination of different methods [8]. Coexistence of pulmonary hamartoma with lung cancer was reported in a study conducted on 14 patients who had undergone resection of which 3 had lung cancer [9]. Pulmonary Hamartomas need to be considered in the differential diagnosis of coin lesions seen on chest imaging as well as recurrent or non-resolving pneumonia.

\section{References}

1. Madewell JE, Feigin DS (1977) Benign tumors of the lung. Semin Roentgenol 12: 175186. [Crossref]

2. Hariqbal Singh, SK Khanna, Vijay Chandran, RK Jetley (1999) Pulmonary Hamartoma. Med J Armed Forces India 55: 79-80. [Crossref]

3. Siegelman SS, Khouri NF, Scott WW Jr, Leo FP, Hamper UM, et al. (1986) Pulmonary hamartoma: CT. Radiology 160: 307-312. [Crossref]

4. Otani Y, Yoshida I, Kawashima O, Yamagishi T, Ishikawa S, et al. (1997) Benign tumors of the lung: a 20-year surgical experience. Surg Today 27: 310-312. [Crossref]

5. Hummel P, Cangiarella JF, Cohen JM, Yang G, Waisman J, et al. (2001) Transthoracic fine-needle aspiration biopsy of pulmonary spindle cell and mesenchymal lesions: a study of 61 cases. Cancer 93: 187-198. [Crossref]

6. Johansson M, Dietrich C, Mandahl N, Hambraeus G (1993) Recombinations of chromosomal bands $6 \mathrm{p} 21$ and $14 \mathrm{q} 24$ characterize pulmonary hamartomas. $\mathrm{Br} J$ Cancer 67: 1236-1241. [Crossref]

7. Sinner WN (1982) Fine-needle biopsy of hamartomas of the lung. AJR Am J Roentgenol 138: 65-69. [Crossref]

8. Tsuyoshi Oguma, Hiroto Takiguchi, Kyoko Niimi, Hiromi Tomomatsu, Katsuyoshi Tomomatsu et al. (2014) Endobronchial Hamartoma as a Cause of Pneumonia. Am J Case Rep 15: 388-392. [Crossref]

9. Matsuda E, Okabe K, Kobayashi S, Hirazawa K, Yamamoto H, et al. (2010) [Pulmonary hamartoma associated with lung cancer]. Kyobu Geka 63: 875-878. [Crossref]

Copyright: (C2018 Chatterji DG. This is an open-access article distributed under the terms of the Creative Commons Attribution License, which permits unrestricted use, distribution, and reproduction in any medium, provided the original author and source are credited. 